\title{
Peripheral odontogenic fibroma: A rare benign gingival tumor and compared with pyogenic granuloma
}

\author{
Jae-Hong Lee*, Seong-Nyum Jeong \\ Department of Periodontology, Institute of Wonkwang Dental Research, Daejeon Dental Hospital, Wonkwang University School of Dentistry, \\ Daejeon, Korea
}

Peripheral odontogenic fibroma (POF, WHO-type) is a relatively rare benign tumor which shows sessile, firm, and exophytic gingival enlargement. Microscopically, a POF is a gingival lesion consisting of scattered and multiple islands of odontogenic epithelial strands and keratinized stratified squamous epithelium with long and thin rete pegs underlying fibrocellular connective tissue. A mature lesion of POF is clinically difficult to distinguish from pyogenic granuloma, due to their similar shapes and colors, and the fact that pyogenic granuloma is a frequently-occurring disease. Therefore, we report a case of POF in a 37-year-old female and compare it with pyogenic granuloma.

Key Words: Gingival overgrowth, Odontogenic tumor, Peripheral odontogenic fibroma, Pyogenic granuloma

(c) This is an open-access article distributed under the terms of the Creative Commons Attribution Non-Commercial License (http://creativecommons.org/licenses/by-nc/4.0) which permits unrestricted noncommercial use, distribution, and reproduction in any medium, provided the original work is properly cited.

\section{INTRODUCTION}

Peripheral odontogenic fibroma (POF, WHO-type) is a relatively rare benign tumor composed of uncapsulated and fibrous connective tissue and containing odontogenic epithelium [1]. In the past, POF was mixed with peripheral ossifying fibroma due to the similarity of clinical and histologic findings [2]. POF is a relatively solid, fixed gingival mass, clinically having a size of $1-3 \mathrm{~cm}$ and showing similar color to surrounding gingiva. Generally, it is reported to proliferate slowly and to cause displacement of the teeth rather than root resorption [2].

POF was defined by the WHO in 1971 as an extraosseous counterpart of central odontogenic fibroma as a fibroblastic neoplasm containing dentin and/or cementum [2]. Central odontogenic fibroma refers to an overgrowth of dental papilla, and is an extremely rare benign tumor that accounts for $0.1 \%$ of all odontogenic tumors [3]. Symptoms of central odontogenic fibroma are usually not perceived. Central odontogenic fibroma has similar manifestations as those of ameloblastoma; it is characterized by multilocular, radiolucent lesions that grow gradually, and have clear borders. Unlike POF, it causes frequent tooth resorption and root separation [4].

When POF occurs, exophytic gingival mass, such as pyogenic granuloma, peripheral ameloblastoma, peripheral giant cell granuloma, peripheral ossifying fibroma need to be differential diagnosed due to similar morphology.

Received June 5, 2018; Revised June 26, 2018; Accepted June 29, 2018

Corresponding author: Jae-Hong Lee, Department of Periodontology, Daejeon Dental Hospital, Wonkwang University School of Dentistry, 77 Dunsan-ro, Seo-gu, Daejeon 35233, Korea.

Tel: +82-42-366-1114, Fax: +82-42-366-1115, E-mail: ljaehong@gmail.com

Copyright $\odot$ 2018, Oral Biology Research Institute 
Especially, the mature lesion of POF is clinically difficult to distinguish from pyogenic granuloma because it has a similar shape and color to POF and is a frequently occurring disease. Therefore, the purpose of this case report is to describe a rare benign gingival tumor of POF in a 37-yearold female and compared with pyogenic granuloma.

\section{CASE}

A 37-year-old female patient presented in the Department of Periodontology, with a localized gingival swelling in relation to interproximal gingiva of mandibular right lateral incisor and canine region. The patient reported spontaneous gingival bleeding for three or four years, and excessive gingival enlargement began to grow about a year ago. The patient also reported that did not have any systemic diseases including hypertension and diabetes mellitus and was not pregnant.
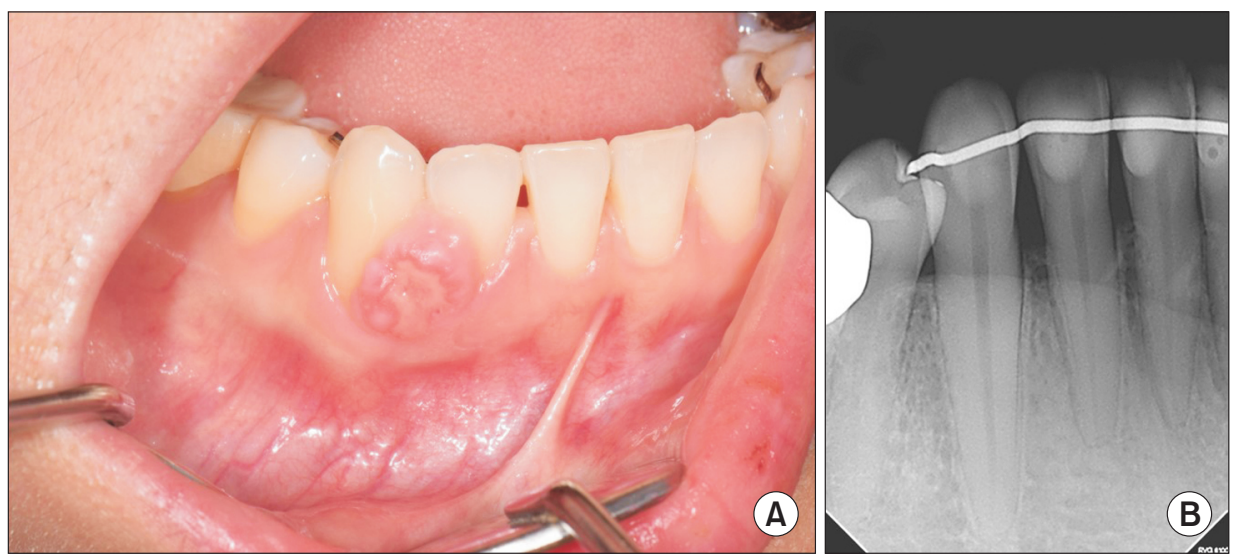

Fig. 1. (A) Clinical photograph showing sessile, firm, exophytic gingival enlargement interproximal gingiva of mandibular right lateral incisor and canine region. (B) Intraoral periapical radiograph of the involved area showed no evidence of marginal and horizontal bone loss, displacement of teeth, and root resorption.
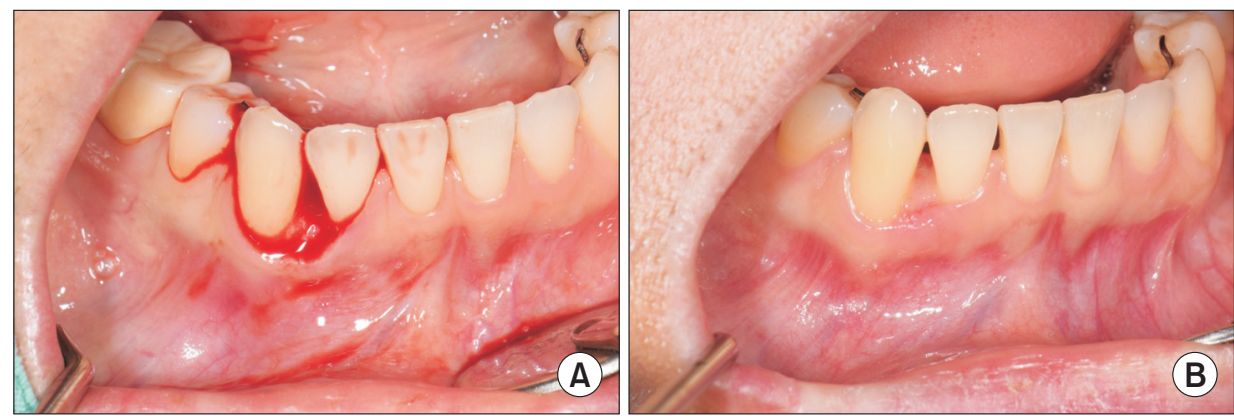

Fig. 2. Clinical photograph. (A) Excisional biopsy after open flap debridement. (B) After 4 weeks follow-up. 
blades (Fig. 2A). After biopsy and complete debridement, the remaining and overlying papilla was sutured with polytetrafluoroethylene monofilament (Biotex; Purgo, Seongnam, Korea). The excised preparation was preserved for histopathological evaluation in 10\% buffered formalin and sent to the Department of Oral pathology. Patient was recalled after 10 days and performed stitch-out. After 4 weeks follow-up, the lesion seemed to in a normal fashion (Fig. 2B).

\section{Histopathological examination}

Microscopically, the hematoxylin and eosin-stained slides showed keratinized and hyperplastic stratified squamous epithelium with long and thin rete pegs underlying fibrous and cellular connective tissue. In addition, non-neoplastic cuboidal/columnar epithelium in the form of a strand was observed to be scattered between the cellular fibrous connective tissue stroma (Fig. 3A). Exophytic gingival lesion also consisted of scattered and multiple islands of odontogenic epithelial strand and chronic inflammatory cells (Fig. 3B).

\section{DISCUSSION}

POF is a very rare gingival disease, and about $1.2 \%$ of all cysts and tumors in the intraoral cavity are diagnosed as POF [2]. POF occurs in local areas that are consistently stimulated, or inflamed. It can occur anywhere where there is connective tissue. Although it affects various age groups from persons in 20 's to 80 's, it commonly occurs in persons in their 10 's to 30 's. It is also 1.2 times more common among female although the incidence difference between the both genders is statistically insignificant [5]. Clinically, it more frequently affects mandibular canines and premolars, and maxillary interdental papilla. The patient in this case report was a young female in her 30's, and had POF in the interdental papilla between the mandibular canines and premolars, which have been commonly observed in similar cases in previous studies.

The pathogenesis of POF remains controversial, it has been also known as 'odontogenic gingival epithelial hamartoma' and 'peripheral ameloblastic fibrodentinoma' because it involves cementum, bone, or other calcification material when viewed histologically [6,7]. A histological study has reported the presence of oxytalan fibers only around the supporting structures of teeth in all patients,
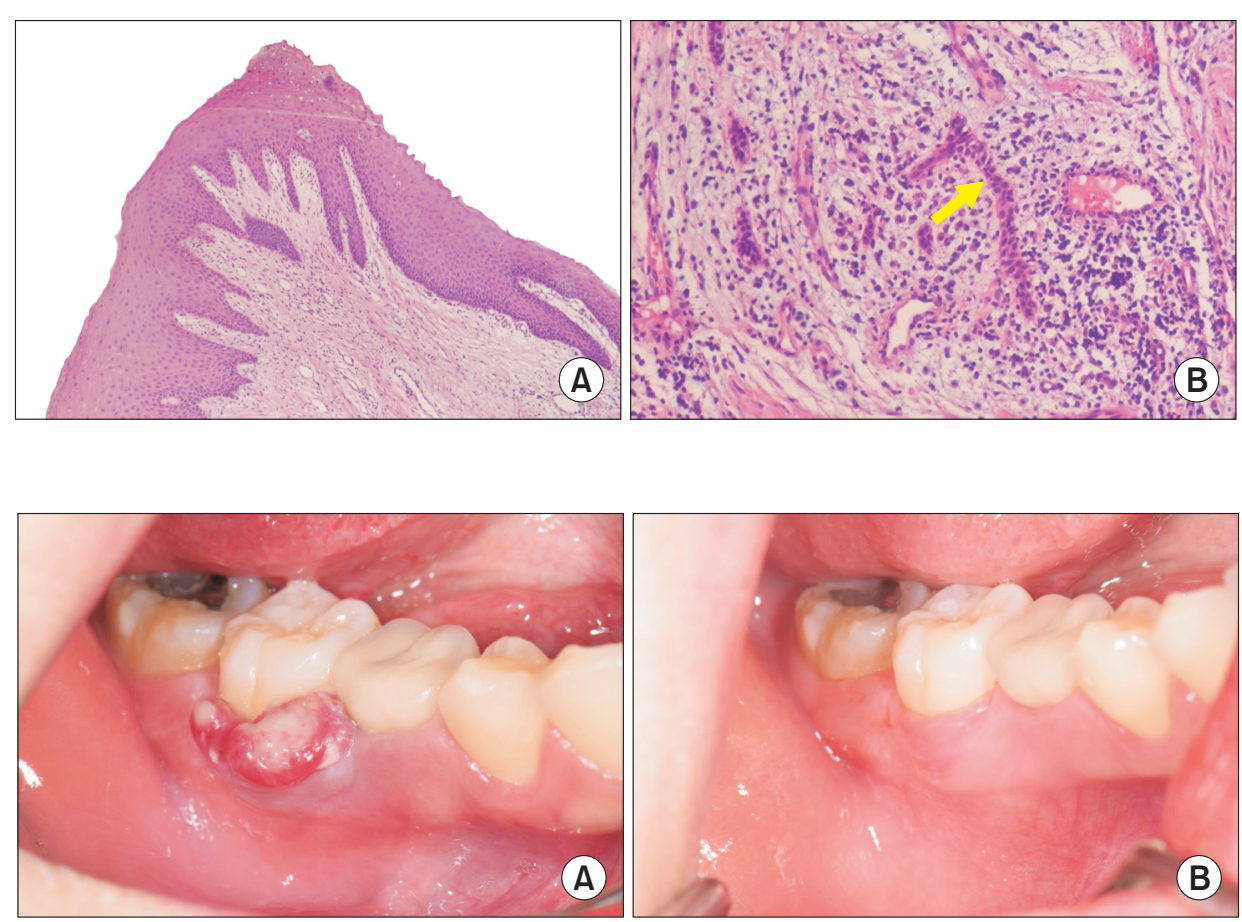

Fig. 3. Photomicrograph of hematoxylin and eosin staining section. (A) Keratinized and hyperplastic stratified squamous epithelium with long and thin rete pegs underlying fibrocellular connective tissue (magnification, $\times 40$ ). (B) Islands of odontogenic epithelial strand, marked by yellow arrow (magnification, $\times 100$ ).

Fig. 4. Clinical photo of a 32-year-old female patient in the first trimester of pregnancy. (A) Exophytic gingival enlargement attached gingiva of mandibular right second molar region and the central portion showed an ulcerous whitish lesion. (B) The size of lesion decreased and subsided significantly after giving birth. 
and therefore, reported that these fibers originated from the periodontal ligament [8]. In this clinical case, evidence of underlying bone and calcification was not found in histological examinations. However, non-neoplastic epithelium or cuboidal/columnar epithelium in the form of a strand was observed to be scattered between the cellular fibrous connective tissue parenchyma [9].

Pyogenic granuloma, a clinically similar mass with POF, is a very common vascular lesion that occurs in the skin and mucous membranes and has also known as 'eruptive hemangioma', 'granulation tissue-type hemangioma', 'granuloma gravidarum', 'lobular capillary hemangioma', and 'pregnancy tumor' [10]. Unlike POF, poor oral hygiene and chronic inflammatory irritation from calculus, ill-fitting restoration, denture, and heavy calculus, physical trauma from chewing and biting, irritation by stimulating food, and hormonal changes (especially in the first trimester of pregnancy) are the main causes of pyogenic granuloma or major deterioration factors (Fig. 4). Pyogenic granuloma is clinically developed more frequently in the maxillary region and it occurs mainly in the buccal gingiva and interproximal papilla [11]. Traumatic fibroma, known as irritation fibroma or fibrous hyperplasia, is an exophytic gingival lesion that occurs very frequently in the lip and oral cavity. It occurs frequently in the buccal and labial mucosa and the lateral surface of the tongue, which is easily exposed to chewing and biting trauma. Therefore, differential diagnosis from fibroma is also needed clinically.

For the patient in this case report, an excisional biopsy was performed with the assumption that the lesion was traumatic irritation induced pyogenic granuloma, and the lesion was diagnosed as POF based on the biopsy results. POF can easily be treated by surgical excision, and recurrence is reported to be rare. However, some studies have reported high recurrence rates considering the low incidence of POF, and poorly performed long-term follow-up in previous studies [12]. Therefore, when POF is confirmed, the possibility of recurrence must be considered even after complete resection, and regular, long-term follow-up must be done.

In conclusion, a histological examination is necessary to differentiate POF from pyogenic granuloma as they show similar clinical manifestations. When POF is confirmed, the possibility of recurrence must be considered even after complete resection, and regular, long-term follow-up must be done.

\section{ACKNOWLEDGEMENTS}

This research was supported by the Basic Science Research Program through the National Research Foundation of Korea (NRF) funded by the Ministry of Science, ICT \& Future Planning (NRF-2017R1C1B5014849).

\section{CONFLICTS OF INTEREST}

The authors declare that they have no competing interests.

\section{ORCID}

\author{
Jae-Hong Lee \\ https://orcid.org/0000-0002-2375-0141 \\ Seong-Nyum Jeong \\ https://orcid.org/0000-0003-4890-989X
}

\section{REFERENCES}

1. Wood NH, Carim R, Ngwenya SP. Diffuse peripheral odontogenic fibroma with concomitant plasma cell gingivitis-a case report and literature review. SADJ 2012;67:448-451.

2. Siar $\mathrm{CH}, \mathrm{Ng} \mathrm{KH}$. Clinicopathological study of peripheral odontogenic fibromas (WHO-type) in Malaysians (196795). Br J Oral Maxillofac Surg 2000;38:19-22. doi: 10.1054/ bjom.1999.0199.

3. Daniels JS. Central odontogenic fibroma of mandible: a case report and review of the literature. Oral Surg Oral Med Oral Pathol Oral Radiol Endod 2004;98:295-300. doi: 10.1016/j.tripleo.2004.01.017.

4. Covani U, Crespi R, Perrini N, Barone A. Central odontogenic fibroma: a case report. Med Oral Patol Oral Cir Bucal 2005;10 Suppl 2:E154-157.

5. Daley TD, Wysocki GP. Peripheral odontogenic fibroma. Oral Surg Oral Med Oral Pathol 1994;78:329-336. doi: 10. 1016/0030-4220(94)90064-7.

6. Baden E, Moskow BS, Moskow R. Odontogenic gingival epithelial hamartoma. J Oral Surg 1968;26:702-714.

7. McKelvy BD, Cherrick HM. Peripheral ameloblastic fibrodentinoma. J Oral Surg 1976;34:826-829. 
8. Wright BA, Jennings EH. Oxytalan fibers in peripheral odontogenic fibromas. A histochemical study of eighteen cases. Oral Surg Oral Med Oral Pathol 1979;48:451-453. doi: 10.1016/0030-4220(79)90077-X.

9. Ficarra G, Sapp JP, Eversole LR. Multiple peripheral odontogenic fibroma, World Health Organization type, and central giant cell granuloma: a case report of an unusual association. J Oral Maxillofac Surg 1993;51:325-328. doi: 10.1016/S0278-2391(10)80186-7.

10. Krishnapillai R, Punnoose K, Angadi PV, Koneru A. Oral pyogenic granuloma--a review of 215 cases in a south
Indian teaching hospital, Karnataka, over a period of 20 years. Oral Maxillofac Surg 2012;16:305-309. doi: 10.1007/ s10006-012-0315-z.

11. Jafarzadeh H, Sanatkhani M, Mohtasham N. Oral pyogenic granuloma: a review. J Oral Sci 2006;48:167-175. doi: 10. 2334/josnusd.48.167.

12. Daley TD, Wysocki GP, Pringle GA. Relative incidence of odontogenic tumors and oral and jaw cysts in a Canadian population. Oral Surg Oral Med Oral Pathol 1994;77:276280. doi: 10.1016/0030-4220(94)90299-2. 